\title{
Chain shifts, strident vowels, and expanded vowel spaces
}

\author{
Matthew Faytak* \\ LSA Annual Meeting, Minneapolis, January 2-5, 2014
}

1. Introduction. Chain shifts among vowels proceed along largely predictable articulatory paths (Labov et al. 1972, Labov 1994): for instance, peripheral vowels tend to raise, and high vowels, butting up against the top of the vowel space, as a rule instead diphthongize or centralize. Labov notes that the "physical parameters of the articulatory apparatus" define the vowel space, and that after enough raising a vowel "cannot become any higher and still be a vowel" (266). This is a reasonable view to draw from the available evidence: only the portion of the possible F1-F2 plane that can be articulated by a human vocal tract while maintaining other canonically vowel-like settings—voicing, laminal airflow, and the resulting largely periodic acoustic output—is taken to be populated by vowel categories.

Counter to this, I argue for a novel type of chain shifting in which high vowels further increase their constriction degree, resulting in vowels realized with heavy coronal or labiodental frication (Connell 2007). I account for the rare but consistent emergence of these vowels through basic principles of dispersion (Liljencrants \& Lindblom 1972): under certain circumstances, vowels may raise, seemingly as part of a chain shift. As a result, tongue height sufficient to produce frication may be integrated into the articulatory vowel space. This change is best accounted for as a push chain, since spontaneous vowel fricativization is not well-motivated in and of itself.

2. Strident or fricative vowels. Fricative vowels are attested in the Bantoid languages (Connell 2007), most Chinese dialects (Dell 1994), some varieties of Swedish (Engstrand et al. 2000), and various Tibeto-Burman languages (Namkung 1996). In this section, I briefly familiarize the reader with the articulation and resulting acoustics of these sounds before moving on to the phenomenon of their development. It should be noted that I use the term "vowel" here given their vowel-like phonotactic behavior or distributional properties (Faytak in press); the acoustic description to follow presents an interesting mismatch with this phonological characterization.

Strident vowels, more frequently known as fricative vowels (Connell 2007), are vowels realized with salient frication that is made by arranging the articulators to produce an obstacle noise source, or a location where a jet of turbulent air may strike a surface at a sharp angle (Shadle 1990). Fricative vowels are thus stridently fricated, with a noise source characteristic either of a strident coronal fricative (e.g. [z]) or a labiodental fricative (e.g. [v]). ${ }^{1}$

Articulatorily, the obstacle noise source is clearly a narrow constriction at either a labiodental or coronal place of articulation. Visual inspection of the lips during production confirms this characteristic for the labiodentals, while static palatography confirms that for Kom and Wanghao $\mathrm{Wu}$, two languages whose fricative vowels are discussed below, the [z]-like vowels are in fact

\footnotetext{
${ }^{*}$ I thank my language consultants, especially Emmanuel Chiabi (Kom), for their time and patience. For their feedback and clarifying criticism, thanks also go to: Keith Johnson, Andrew Garrett, Larry Hyman, Jack Merrill, and audiences at the Acoustical Society of America (166th meeting, San Francisco) and Stanford's P-Interest workshop. Authors: Matthew Faytak, University of California, Berkeley (mf@ berkeley.edu).

${ }^{1}$ Although labiodentals are never counted as sibilants, they are frequently counted as stridents in opposition to bilabial fricatives. See, for instance, Utman \& Blumstein (1994).
} 

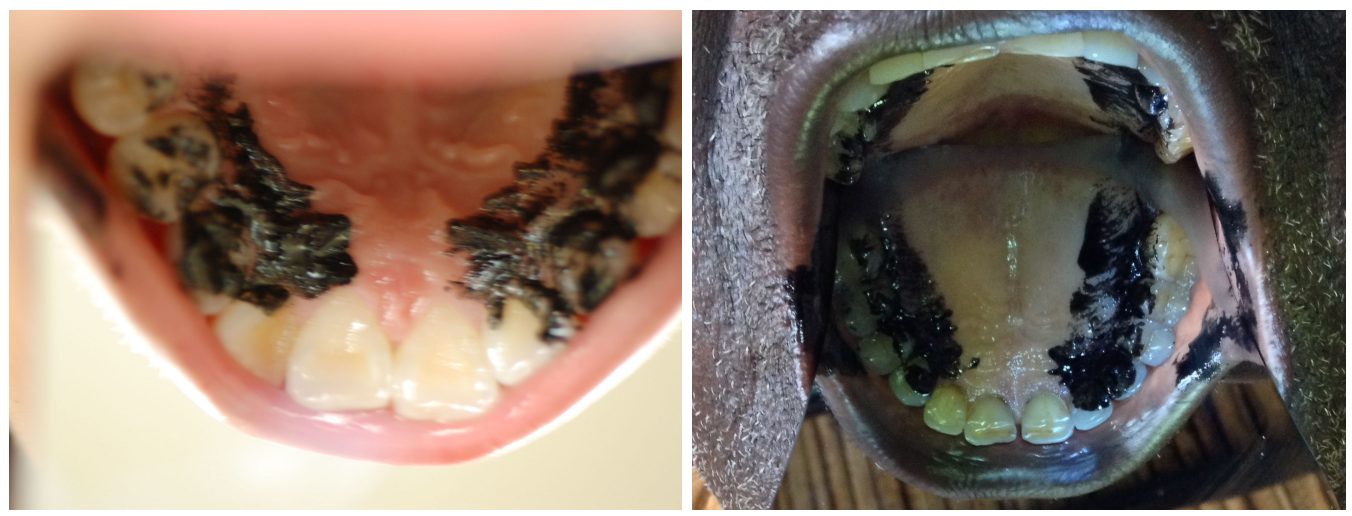

Figure 1: Left: Wanghao Wu [bz̀] 'to compare, compete'. Right: Kom [ə̄bź] 'goat'.

articulated like strident fricatives, with a narrow constriction located near the alveolar ridge (Figure 1). Coronal vowels with secondary lip rounding are rare but also attested, often in phonemic contrast with an unrounded coronal vowel (see Section 3.2).

3. Case studies. Below, I consider two cases in which fricative vowels appear to be the end point of a raising chain shift. Although further research is needed to determine why strident frication is the end posint of raising the tongue body-strident frication involves several other articulators working in concert (Shadle 1990, Iskarous et al. 2011), and it is as such unlikely to be a direct consequence of tongue body raising alone - the patterns below can be viewed as a consequence of a high vowel being pushed beyond the usual bounds of the vowel space by other encroaching categories.

3.1. Central Ring. The Central Ring languages, a subgroup of Grassfields Bantu spoken in northwestern Cameroon, have undergone a fricativizing chain shift that has affected their back vowels (Figure 2). Given that no prior phonological reconstruction has been carried out on the Ring languages specifically, I offer tentative reconstructions from my own notes for the sake of analyzing the chain shifts at hand. I reconstruct Proto-Central Ring (PCR) with three back vowels: ${ }^{*} o, * v$, and $* u$. In Bum, a phonologically conservative Central Ring language, $* v$ and $* o$ merge to /o/. Kom and Oku, in contrast, undergo a short raising chain: $* v$ raises to $/ \mathrm{u} /$, and $* u$ is fricativized in turn.

The resulting reflexes are a syllabic /v/ in Kom and a "labiodentalizing" schwa in Oku: for the latter, Davis (1992) describes a phoneme /ə/ which is realized as /və/ when preceded by a labial, postalveolar, or velar initial. Based on recent work of my own on Oku, however, this is an incomplete generalization: /ə/ is also realized as /zə/ when preceded by a coronal initial. Oku's $/ \partial /$ is most likely derived from intermediate $* v$ of the sort seen in Kom, subjected to a sort of breaking (e.g. $*_{\mathrm{v}}>*_{\mathrm{v}} \mathrm{\gamma} / \mathrm{\partial} /$ ). The realization as $/(\mathrm{z}) \partial /$ is more difficult to explain at this point, but likely has to do with assimilation to the preceding coronal initial (e.g. *svəə > szəə) 'fish'.

It was alluded to in Section 2 that Kom has an additional fricative vowel /z/. It also appears to have arisen through a chain shift, roughly $*_{i j}>*_{i}>/ z /$. However, there are numerous splits along this path (a number of $* i>/ \mathrm{u} /$ in Kom, for instance), and the reconstructible value of $* i y$ is possibly not monophthongal. As such, I leave this second Center Ring chain shift for future comparative research. 


\begin{tabular}{|c|c|c|c|c|}
\hline PCR & & Kom & $\mathrm{Oku}$ & Bum \\
\hline$*$-tw & Head & a-tu & kə-tuu & a-to \\
\hline *-wum & Egg & i-wum & i-wum & i-wum \\
\hline$*_{-S \mho}$ & To Wash & & suu & so \\
\hline$*_{\text {-sws }}$ & Pepper & fə-sus & fə-sus & - \\
\hline *-ygu & Fowl & ว-ngv & $\overline{\mathrm{y}}$-gvəə & $a-\eta g u$ \\
\hline *-tfuy & Knot & tovg & tvon & tou \\
\hline *-wum & Ten & i-vm & i-vəm & i-wum \\
\hline$*_{\text {-su }}$ & Fish & $\partial-\int v$ & szəə & - \\
\hline$*_{\text {-sus }}$ & To Pour Out & $-\int \mathrm{vs}$ & -SZOS & -suh \\
\hline
\end{tabular}

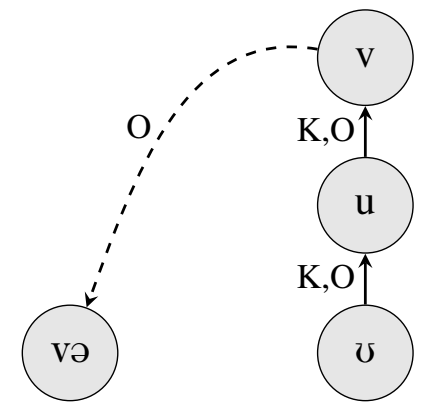

Figure 2: Left: Data from Hyman \& Jisa (1978); Kom and Oku checked with my own recordings and (Davis 1992), respectively. Tone is omitted. Right: The chain shift at issue; languages affected by each step identified by initial.

3.2. Wu CHINESE. The Wu subgroup of Chinese languages exhibits a similar spirantizing chain shift, this time affecting the front rounded and unrounded vowels and ending in rounded and unrounded coronal fricative vowels (Figure 3). The starting point for comparison here is Ballard (1969)'s reconstructions of Proto-Wu (PWu); I further draw from existing compendia of Wu lexical material, largely Qian (1992).

Starting with the loss of PWu *-n, nasalization shifts to syllable nuclei. Danyang and Liyang further monophthongize and denasalize these rhymes (Li et al. 1995); this can be contrasted with Taiping, which is more phonologically conservative and retains nasalized diphthongs for this set. The rhymes resulting from these shifts are close to $\mathrm{PWu} * i$ and $* y$; as a result reflexes of the latter in Danyang and Liyang have developed into rhymes given by Qian (1992) as $/ \mathbf{i}_{z} /$ and $/ \mathrm{y}_{z} /$.

\begin{tabular}{|c|c|c|c|c|}
\hline \multicolumn{2}{|l|}{$\mathrm{PWu}$} & Danyang & Liyang & Taiping \\
\hline *pjen III & 变 To Change & $\mathrm{pi}^{324}$ & $\mathrm{pi}^{412}$ & pie $\tilde{e}^{35}$ \\
\hline *p'jen III & 片 Slice & $\mathrm{p}^{\mathrm{h}} \mathrm{I}^{324}$ & $\mathrm{p}^{\mathrm{h}} \mathrm{i}^{412}$ & $\mathrm{p}^{\mathrm{h}} \mathrm{i} \tilde{\mathrm{e}}^{324}$ \\
\hline *hjenI & 盐 Salt & $\mathrm{fi}^{213}$ & $i^{323}$ & fiie $\tilde{e}^{312}$ \\
\hline$* \mathbf{k u} \mathbf{\Lambda} \mathbf{n}^{\mathbf{I}}$ & 捐 To Donate & $t_{6} \mathrm{Y}^{22}$ & $\mathrm{t}_{6 \mathrm{Yr}}{ }^{445}$ & t6y $\tilde{\mathrm{e}}^{523}$ \\
\hline *Pyrn II & 远 Far & $Y^{44}$ & PYo 445 & fyó $\tilde{e}^{22}$ \\
\hline$* p i^{I I I}$ & 闭 To Close & $\mathrm{pi}_{z}{ }^{324}$ & $\mathrm{pi}_{z}{ }^{412}$ & $\mathrm{pi}^{35}$ \\
\hline$*^{*}{ }^{\prime} \mathbf{i}^{\mathrm{III}}$ & 屁 Flatulence & $\mathrm{p}^{\mathrm{h}} \mathrm{i}_{z}{ }^{324}$ & $\mathrm{p}^{\mathrm{h}} \mathrm{i}_{z}{ }^{412}$ & $\mathrm{p}^{\mathrm{h}} \mathrm{i}^{324}$ \\
\hline$* \mathbf{f i} \mathbf{i}^{\mathrm{I}}$ & 移 To Shift & $\mathrm{fi}_{z}{ }^{213}$ & $\mathrm{i}_{z}^{323}$ & $\mathrm{hi}^{312}$ \\
\hline$* \mathbf{k y} \mathbf{I}$ & 居 Residence & $t_{6 y z} z^{22}$ & t6yz $z^{445}$ & $t_{6} y^{523}$ \\
\hline$* \mathbf{P y}^{\text {II }}$ & 雨 Rain & $y_{z}^{44}$ & $P y_{z}^{445}$ & $6 y^{22}$ \\
\hline
\end{tabular}

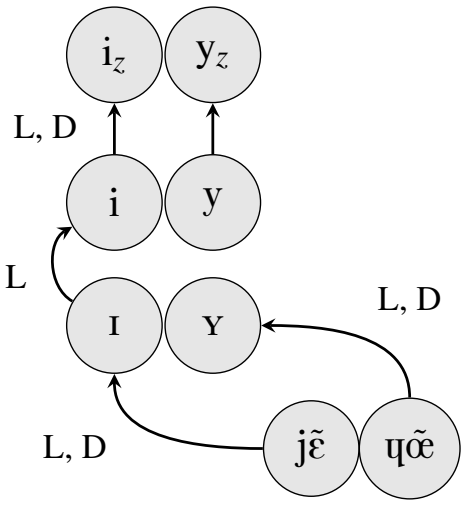

Figure 3: Left: Proto-Wu from Ballard (1969), modern Wu from Qian (1992). Reconstructions for 'flatulence' and 'salt' are extrapolated from regular correspondences between Qian and Ballard's data. Right: Chain shifts at issue, languages affected by each step identified by initial.

Qian notes that both $/ \mathrm{i}_{z} /$ and $/ \mathrm{y}_{z} /$ are "accompanied by a [z] sound" (12), but it is not immediately clear what the phonetic identity of these sounds is. I find compelling evidence for identifying $/ i_{z} /$ and $/ y_{z} /$ with fricative vowels of the sort described above. First, numerous 
descriptions of similarly spirantized vowels exist for closely related Wu languages, for instance Zhenhai and Shanghai Wu (Zhu 2006). Secondly, and more concretely, I have had the opportunity to elicit lexical forms from a speaker of Wanghao, a Wu dialect from the same dialect area as Danyang and Liyang; without much question, the relevant lexemes are produced with strident frication as predicted. A palatogram from the unrounded coronal vowel is provided in Figure 1.

4. Concluding notes. Spirantizing chain shifts, although rare, can be elegantly explained as resulting from "raising" out of a crowded high vowel space. Most likely, the light fricative noise that is often produced by very high vowels is phonologized as a cue to these phonological categories under pressure from encroaching vowels. The resulting vowel systems present a phonetics-phonology mismatch that has been discussed elsewhere (Faytak in press): successive sound changes alter the production of high vowels, but the distribution of the category does not change, resulting in phonetic obstruents that function, for all intents and purposes, as vowels.

The data presented above requires us to expand the notion of the "vowel space" beyond existing acoustic-articulatory definitions. Typically, the vowel space excludes tongue heights high enough to induce turbulent airflow. The data above instead suggests that many languages' vowel spaces may range over a continuum of constriction apertures that are conventionally taken as semivocalic or even consonantal (Padgett 2008).

\section{References}

Ballard, William L. 1969. Phonological History of Wu: University of California, Berkeley dissertation. Connell, Bruce. 2007. Mambila fricative vowels and Bantu spirantization. Africana Linguistica 13.

Davis, Leslie. 1992. A segmental phonology of the Oku language. SIL Cameroon.

Dell, François. 1994. Consonnes à prolongement syllabique en Chine. Cahiers de linguistique-Asie orientale 23(1).

Engstrand, Olle, Sven Björsten, Björn Lindblom, Gösta. Bruce \& Anders Eriksson. 2000. Hur udda är Viby-i? Experimentella och typologiska observationer. Folkmålsstudier 39. 83-95.

Faytak, Matthew. in press. Compiling sonority scales with obstruent vowels. Proceedings of the annual meeting of the Berkeley Linguistics Society 38.

Hyman, Larry M. \& Harriet Jisa. 1978. Word list of comparative Ring. Unpublished ms.

Iskarous, Khalil, Christine H. Shadle \& Michael I. Proctor. 2011. Articulatory-acoustic kinematics: The production of American English /s/. The Journal of the Acoustical Society of America 129(2). 944-954.

Labov, William. 1994. Principles of Linguistic Change, Volume 1: Internal Factors. Wiley.

Labov, William, M. Yaeger \& R. Steiner. 1972. A quantitative study of sound change in progress. Report on NSF Contract NSF-GS-3287.

Li, Rong et al. 1995. Danyang fangyan cidian [Dictionary of the Danyang dialect]. Jiangsu jiaoyu chubanshe [Jiangsu Education Press].

Liljencrants, Johan \& Björn Lindblom. 1972. Numerical simulation of vowel quality systems: The role of perceptual contrast. Language 839-862.

Namkung, Jun. 1996. Phonological inventories of Tibeto-Burman languages. STEDT.

Padgett, Jaye. 2008. Glides, vowels, and features. Lingua 118(12). 1937-1955.

Qian, Nairong. 1992. Dangdai Wuyu yanjiu [Studies in modern Wu languages]. Shanghai jiaoyu chubanshe [Shanghai Education Press].

Shadle, Christine H. 1990. Articulatory-acoustic relationships in fricative consonants. In Speech production and speech modelling, 187-209. Springer.

Utman, Jennifer A. \& Sheila E. Blumstein. 1994. The influence of language on the acoustic properties of phonetic features: A study of the feature [strident] in Ewe and English. Phonetica 51(4). 221-238.

Zhu, Xiaonong. 2006. A grammar of Shanghai Wu. Lincom Europa. 